\title{
Anesthetic Management of a Delayed Carinal Resection Following Traumatic Disruption
}

\author{
Kevin A. Blackney, Paul H. Alfille \\ Department of Anesthesia, Critical Care and Pain Medicine, Massachusetts General Hospital, Boston, USA \\ Email: kblackney@partners.org, palfille@partners.org
}

Received 16 August 2014; revised 19 September 2014; accepted 1 October 2014

Copyright (C) 2014 by authors and Scientific Research Publishing Inc.

This work is licensed under the Creative Commons Attribution International License (CC BY). http://creativecommons.org/licenses/by/4.0/

c) (i) Open Access

\begin{abstract}
Resecting and reconstructing the carina is an anesthetic challenge in the best of circumstances. The surgery is meticulous and requires access to the trachea and bronchi, ruling out traditional lung isolation techniques. When resection of the carina is due to traumatic disruption, confounding thoracic injuries can make adequate ventilation and oxygenation difficult, especially when only one lung is available for ventilation. ECMO is an intervention that provides sufficient oxygenation and an unimpeded surgical field. ECMO also allows use of smaller airway management tools that can be used to ventilate the dependent lung, thus preventing atelectasis and producing better postoperative outcomes.
\end{abstract}

\section{Keywords}

Trauma, Carinal Disruption, Airway Management

\section{Introduction}

Tracheal surgery requires high levels of coordination and communication between the surgical and anesthesia teams to produce successful outcomes. Anesthetic management for resection of the carina after a traumatic disruption is even more complicated as other thoracic injuries may make the patient unable to tolerate one lung ventilation $(\mathrm{OLV})$. Here we present a case of a young male who suffered a right proximal mainstem injury after a motor vehicle accident (MVA), whose preoperative period was complicated by acute respiratory distress syndrome (ARDS) and an extremely high sedation requirement which led to a challenging intraoperative course.

The patient gave consent for publication of this case report. 


\section{Case Description}

36-year-old male presented with polytrauma after an MVA including a carinal disruption. Other injuries included bilateral aspiration pneumonia, pulmonary contusions, right pneumothorax, pneumomediastinum and pneumopericardium. Bronchoscopic exam showed a 1.2-cm longitudinal tear on the anterosuperior aspect of the right mainstem bronchus, 2-cm from the carina (Figure 1). The patient was admitted to the surgical intensive care unit (SICU) for mechanical ventilation, stabilization and improvement of clinical status. Complicating factors preoperatively included a high positive end expiratory pressure (PEEP) requirement, ARDS, and a high sedation requirement (Fentanyl $500 \mathrm{mcg} / \mathrm{hr}$, Midazolam $4 \mathrm{mg} / \mathrm{hr}$ and Ketamine $4 \mathrm{mcg} / \mathrm{kg} / \mathrm{min}$ ) to facilitate adequate ventilation. A tracheostomy was placed while in the SICU.

On the day of surgery, the tracheostomy was removed as we performed an oral fiberoptic intubation with a 40-cm single lumen endotracheal tube (ETT) specially constructed for endobronchial ventilation. He was placed in the left lateral decubitus position for thoracic epidural placement and surgical preparation, and his lung was isolated. His oxygen saturation rapidly decreased to $65 \%$, and despite numerous interventions including adjustments in PEEP, increasing the fraction of inspired oxygen $\left(\mathrm{FiO}_{2}\right)$, increasing his mean arterial pressure (MAP) and administering inhaled nitric oxide, he was unable to attain satisfactory oxygen levels for surgery. The ETT was withdrawn to the trachea and after discussion with the surgical team, it was decided that continuous positive airway pressure (CPAP) to his right lung would be problematic. Thus, venovenous extracorporeal membrane oxygenation (VV-ECMO) was the best option.

Lung isolation was again established ventilating his left lung thus supplementing the VV-ECMO and decreasing atelectasis formation in the dependent lung. The case proceeded without major complications. Analgesia was provided via his epidural supplemented by high doses of intravenous (IV) narcotic to prevent withdrawal and agitation. Once the anastamosis was complete, the patient was quickly transitioned to pressure support ventilation (PSV) via a newly placed tracheostomy tube and the VV-ECMO was decannulated. His analgesia via epidural and IV narcotic provided adequate pain relief and mild sedation. He was ultimately discharged from the hospital three weeks later.

\section{Discussion}

The complexity of carinal resections is reflected in its overall 7.7\% - 12.7\% operative mortality [1]-[4]. From the surgical perspective, obstacles to successful resection include satisfactory mobilization and dissection of the carina as well as creating an anastamosis that provides adequate tension and avoids devascularization [2]. For the anesthetist, delivering sufficient oxygenation and ventilation while providing a non-obstructed surgical field can be daunting. The first published case report of anesthetic management of a carinal resection was in 1951, passive oxygenation through a catheter in to the non-operative lung and prolonged apnea without ventilation during resection were the approaches used [5]. Like most subsequent publications of the procedure, that case involved a malignant resection whereby the patient was deemed healthy enough to tolerate surgery.

The anesthestic management of a trauma patient undergoing carinal resection is more complicated due to associated thoracic injuries. Tracheobronchial disruptions are involved in $0.5 \%-2 \%$ of all severe blunt trauma, and 59\% of these injuries are the result of an MVA [6]. Up to $80 \%$ of patients with tracheobronchial injuries die

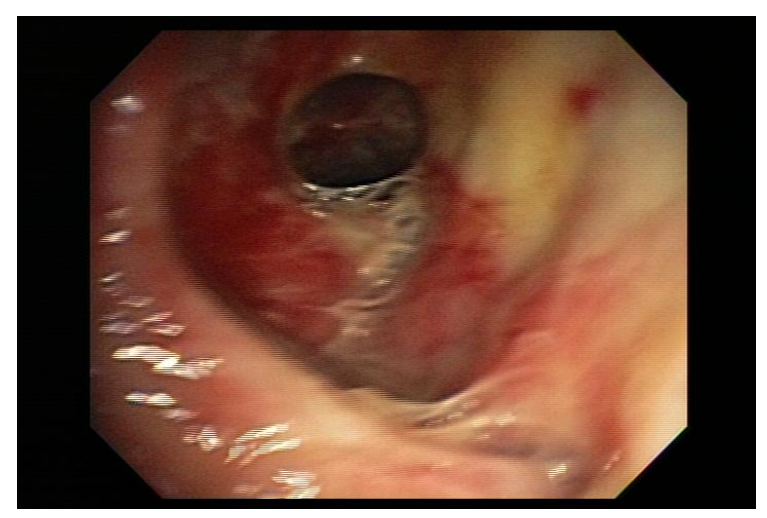

Figure 1. Bronchosopic image of carinal tear. 
within the first 2 hours, though the rate of patients surviving to the hospital is increasing due to improved prehospital care [6]-[8]. The most common initial signs of tracheobronchial disruption are dyspnea and subcutaneous emphysema, with pneumomediastinum and pneumothorax being seen on imaging [7]. Our patient was initially intubated enroute, and bronchoscopy upon arrival revealed the right mainstem tear, the right side being the most frequent site of injury [9]. Fortunately, PPV was tolerated by this patient with an ETT above the lesion, which is not always true with tracheal disruption.

Our patient remained in the SICU for 2 weeks for medical optimization. Delaying repair is not uncommon, and often indicated after trauma, but this delay can change management as new complications may arise. There are case reports of patients returning up to 6 months after a major trauma where a tracheobronchial disruption is discovered, often with dyspnea or persistent pneumonia as the presenting symptom [10] [11]. Furthermore, a recent case series showed patients admitted with traumatic tracheobronchial injuries had no difference in outcome whether managed conservatively or with surgery, other than reduced ICU and hospital stay in the surgical group [12]. Our patient was stable enough to delay and allow optimization of his pulmonary status, though he required extremely high sedation and PEEP to promote vent synchrony.

There are two surgical approaches for carinal surgery; a thoracotomy is most common, though a median sternotomy can be considered as well [1] [2] [4]. OLV is often required to provide the best surgical field. For our patient, we did not feel that a double lumen tube (DLT) would be appropriate due to the shear bulk of that ETT and location to the injury. A DLT would greatly impede the surgeon's ability to mobilize and dissect the carina. However, DLTs have been used successfully in carinal surgery and some even advocate for use post-operatively to limit PPV on the anastamosis [13]. For the same reasons we avoided a DLT, we felt a bronchial blocker or uninvent tube would not be an option either, though these tubes have been used [14].

To provide OLV, we performed an oral fiberoptic intubation, as the surgical team withdrew the patient's tracheostomy tube, with a long single lumen ETT. These long single lumen tubes, produced by Fuji Systems, are $40 \mathrm{~cm}$ in length, wire reinforced, pliable and have a small cuff with little tubing beyond thus providing minimal bulk [15]. Under fiberoptic guidance, we directed this ETT in to the left mainstem bronchus. Due to the pliability of this tube and short cuff, we frequently had to reposition throughout the case.

As noted in the case presentation, our patient did not tolerate OLV despite multiple interventions to improve hypoxic pulmonary vasoconstriction (HPV) on the operative side and improve pulmonary artery dilation on the dependent side [16]. We therefore considered our contingency plans. Currently, cross-field ventilation is the most common practice for carinal resections [15]. This approach has been used successfully in the acute setting with traumatic disruptions, before the onset of secondary injury such as ARDS [8]. With this approach, a sterile circuit is connected through, or distal to, the carinal injury and then passed from the operative field to the anesthesiologist. This creates a situation where both lungs can be ventilated independently [15]. However, cross-field ventilation is challenging for the surgeon during carinal surgery.

Another approach is use of high frequency jet ventilation (HFJV) to the operative side. Airway exchange catheters and suction tubing have been used for this purpose [13] [17] [18]. In the presence of ARDS, we were uncertain that HFJV would be effective, and there was a risk of compounding lung injury from regional overinflation. CPAP is another method to improve oxygenation by providing PEEP to the operative, non-dependent lung, but requires an intact airway which we did not have [19] [20].

Thus, VV-ECMO provided the most stable delivery of oxygen with the best operative field. During carinal resections, it is not uncommon for the patient to require ECMO; more recent case reports have involved its use in carnal resections [15] [21] [22]. There are three types of ECMO; VV-ECMO which is used in respiratory failure, venoarterial ECMO used in cardiac failure and arteriovenous ECMO used for acute lung injury [23]. While ECMO can significantly improve arterial oxygenation, supplementation may be required through means described above. Keeyapaj et al. described the use of VV-ECMO with an airway exchange catheter supplying continuous oxygen flow to the operative side [21]. We elected to supplement oxygenation and prevent atelectasis to the dependent lung by ventilating through the long single lumen ETT while keeping the inspiratory pressure low.

In these surgeries, PPV post-operatively should be avoided. In their review of 134 carinal resections, Mitchell et al. showed that PPV is the leading predictor of post-operative mortality $(\mathrm{P}=0.001)$ [2]. We placed an asleep thoracic epidural for intra-op and post-operative pain control, however, because the patient had been on high doses of sedatives for a prolonged period pre-operatively, we dosed large amounts of opioids intra-operatively to prevent agitation and withdrawal upon emergence. All of this allowed successful transfer to PSV post-opera- 
tively. With two lung ventilation and improved right mainstem bronchial caliber, ventilation was improved over the pre-operative state.

VV-ECMO is an effective approach to carinal surgery, especially in patients with ARDS. Coupled with well designed endobronchial tubes, VV-ECMO allows excellent operative conditions while lowering the risk of worsening lung injury. Lung protective ventilation is important in these cases, and the use of VV-ECMO allows for more conservative ventilation of the dependent lung and better patient outcome.

\section{References}

[1] Liu, X.Y., Liu, F.Y., Wang, Z. and Chen, G. (2009) Management and Surgical Resection for Tumors of the Trachea and Carina: Experience with 32 Patients. World Journal of Surgery, 33, 2593-2598. http://dx.doi.org/10.1007/s00268-009-0258-1

[2] Mitchell, J.D., Mathisen, M.J., Wright, C.D., Wain, J.C., Donahue, D.M., Moncure, A.C. and Grillo, H.C. (1999) Clinical Experience with Carinal Resection. Journal of Thoracic and Cardiovascular Surgery, 117, 39-53. http://dx.doi.org/10.1016/S0022-5223(99)70468-X

[3] Parissis, H. and Young, V. (2010) Carinal Surgery: Experience of a Single Center and Review of the Current Literature. Journal of Cardiothoracic Surgery, 5, 1-7.

[4] Regnard, J.F., Perrotin, C., Giovannetti, R., Schussler, O., Petino, A., Spaggiari, L., Alifano, M. and Magdeleinat, P. (2005) Resection for Tumors with Carinal Involvement: Technical Aspects, Results, and Prognostic Factors. Annals of Thoracic Surgery, 80, 1841-1846. http://dx.doi.org/10.1016/j.athoracsur.2005.04.032

[5] Friedman, J.B. and Emma, E. (1951) A Consideration of Anesthesia during Carinal Resection. Anesthesiology, 12, 740-744. http://dx.doi.org/10.1097/00000542-195111000-00010

[6] Welter, S. (2014) Repair of Tracheobronchial Injuries. Thoracic Surgery Clinics, 24, 41-50. http://dx.doi.org/10.1016/j.thorsurg.2013.10.006

[7] Karmey-Jones, R. and Wood, D.E. (2007) Traumatic Injury to the Trachea and Bronchus. Thoracic Surgery Clinics, 17, 35-46. http://dx.doi.org/10.1016/j.thorsurg.2007.03.005

[8] Senghal, S., Chance, J.C. and Steliga, M.A. (2014) Thoracic Anesthesia and Cross Field Ventilation for Tracheobronchial injuries: A Challenge for Anesthesiologists. Case Reports in Anesthesiology, 2014, Article ID: 972762.

[9] Karmey-Jones, R., Avinsino, J. and Stern, E.J. (2003) CT of Blunt Tracheal Injury. American Journal of Roentgenology, 180, 1670. http://dx.doi.org/10.2214/ajr.180.6.1801670

[10] Glazer, E.S. and Meyerson, S.L. (2008) Delayed Presentation and Treatment of Tracheobronchial Injuries Due to Blunt Trauma. Journal of Surgical Education, 65, 302-308. http://dx.doi.org/10.1016/j.jsurg.2008.06.006

[11] Jain, V., Sengar, M., Mohta, A., Dublish, S. and Sethi, G.R. (2013) Delayed Repair of Posttraumatic Bronchial Transection. Journal of Pediatric Surgery, 48, 1609-1612. http://dx.doi.org/10.1016/j.jpedsurg.2013.05.015

[12] Alassal, M.A., Ibrahim, B.M. and Elsadeck, N. (2014) Traumatic Intrathoracic Tracheobronchial Injuries. Asian Cardiovascular and Thoracic Annals, 22, 816-823.

[13] Naghibi, K., Hashemi, S.L. and Sajedi, P. (2003) Anaesthetic Management of Tracheobronchial Rupture Following Blunt Chest Trauma. Acta Anaesthesiologica Scandinavica, 47, 901-903. http://dx.doi.org/10.1034/j.1399-6576.2003.00179.x

[14] Chin, J.H., Lee, E.H., Choi, D.K. and Choi, I.C. (2010) High Frequency Jet Ventilation of One Lung Using a Bronchial Blocker of Univent during Carinal Resection. Journal of Korean Medical Science, 25, 1083-1085. http://dx.doi.org/10.3346/jkms.2010.25.7.1083

[15] Wilkey, B.J., Alfille, P., Weitzel, N.S. and Puskas, F. (2012) Anesthesia for Tracheobronchial Surgery. Seminars in Cardiothoracic and Vascular Anesthesia, 16, 209-219. http://dx.doi.org/10.1177/1089253212464715

[16] Benumof, J.L. (1985) One-Lung Ventilation and Hypoxic Pulmonary Vasoconstriction: Implications for Anesthetic Management. Anesthesia \& Analgesia, 64, 821-833. http://dx.doi.org/10.1213/00000539-198508000-00014

[17] Murthy, T. (2009) Anaesthetic Management of Carinal Resection and Reconstruction-A Case Report. Indian Journal of Anaesthesia, 53, 340-343.

[18] Perera, E.R., Vidic, D.M. and Zivot, J. (1993) Carinal Resection with Two High-Frequency Jet Ventilation Delivery Systems. Canadian Journal of Anaesthesia, 40, 59-63. http://dx.doi.org/10.1007/BF03009320

[19] Kim, Y.D., Ko, S., Kim, D., Lim, H., Lee, J.H. and Kim, M.H. (2012) The Effects of Incremental Continuous Positive Airway Pressure on PaO2/Shunt in OLV. Korean Journal of Anesthesiology, 62, 256-259. http://dx.doi.org/10.4097/kjae.2012.62.3.256

[20] Lewis, J.W., Serwin, J.P., Gabriel, F.S., Bastanfar, M. and Jacobsen, G. (1992) The Utility of a Double Lumen Tube 
for One-Lung Ventilation in a Variety of Non-Cardiac Thoracic Surgical Procedures. Journal of Cardiothoracic and Vascular Anesthesia, 6, 705-710. http://dx.doi.org/10.1016/1053-0770(92)90056-D

[21] Keeyapaj, W. and Alfirevic, A. (2012) Carinal Resection Using an Airway Exchange Catheter-Assisted Venovenous ECMO Technique. Canadian Journal of Anesthesia, 59, 1075-1076. http://dx.doi.org/10.1007/s12630-012-9773-X

[22] Lei, J., Su, K., Li, X.F., Zhou, Y.A., Han, Y., Huang, L.J. and Wang, X.P. (2010) ECMO-Assisted Carinal Resection and Reconstruction after Left Pneumonectomy. Journal of Cardiothoracic Surgery, 5, 1-3.

[23] Odonkor, P.N., Stansbury, L., Garcia, J.P., Rock, P., Deshpande, S.P. and Grigore, A.M. (2013) Perioperative Management of Adult Patients on Extracopreal Membrane Oxygenation Support. Journal of Cardiothoracic and Vascular Anesthesia, 27, 329-344. http://dx.doi.org/10.1053/j.jvca.2012.09.023 
Scientific Research Publishing (SCIRP) is one of the largest Open Access journal publishers. It is currently publishing more than 200 open access, online, peer-reviewed journals covering a wide range of academic disciplines. SCIRP serves the worldwide academic communities and contributes to the progress and application of science with its publication.

Other selected journals from SCIRP are listed as below. Submit your manuscript to us via either submit@scirp.org or Online Submission Portal.
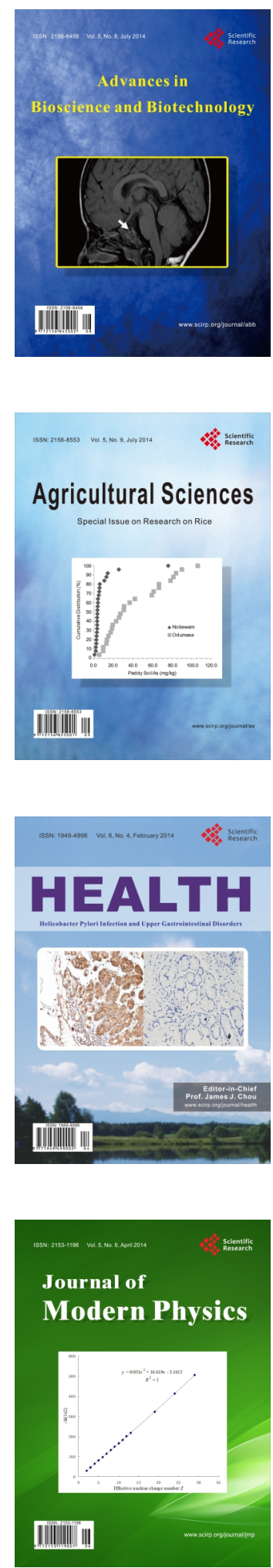
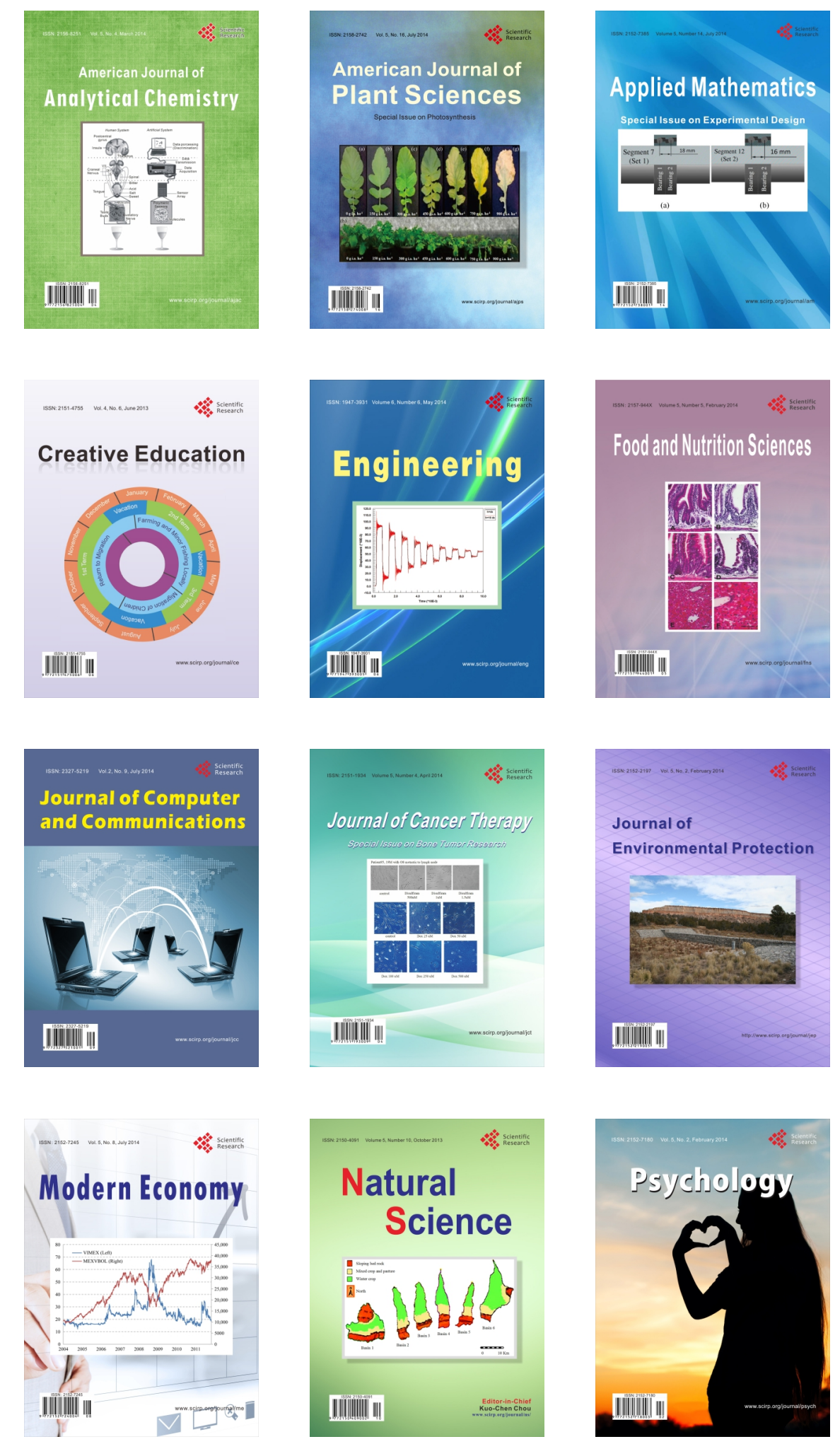